\title{
PERCEPÇÕES SOBRE PRÁTICAS DE CON- SUMO DAS MULHERES NO CONTEXTO DO INSTITUTO FEDERAL DE EDUCAÇÃO, CIÊNCIA E TECNOLOGIA DE SERGIPE-IFS
}

\author{
Rosana Rosa Siqueira
}

Maria José Nascimento

\section{RESUMO}

O presente estudo busca analisar as percepções sobre práticas de consumo das mulheres no contexto do IFS. As análises são pautadas no questionamento acerca das preocupações ambientais na agenda de consumo das mulheres. O estudo realizado no período de 2013 a 2015 caracterizase como uma pesquisa explicativa qualitativa e quantitativa centrada na abordagem fenomenológica proposta por Alfred Schutz e pressupostos da Análise de Conteúdo segundo Bardin (1977). Os dados revelaram que o consumo surge como forma de melhorar as condições de vida e "recompensar" os esforços empreendidos por meio do trabalho, seja este formal ou informal. Nota-se inclusive a dificuldade de vislumbrar um viés ético capaz de atender a necessidade de ações que reduzam os impactos socioambientais atrelados à produção e ao consumo sem que o consumidor sinta-se sacrificado diante da insaciabilidade volátil de suas necessidades. Assim, o percebido ainda não se concretiza de forma plena no vivido destas mulheres, pois alguns obstáculos ainda atrapalham participações efetivas e contínuas.

Palavras-chaves: Mulher, consumo, sustentabilidade. 


\section{ABSTRACT}

This study investigates the perceptions of consumption practices of women in the IFS context. The analysis is grounded in inquiry about the environmental concerns on consumer agenda of women. The study conducted from 2013 to 2015 is characterized as a qualitative and quantitative explanatory research focused on phenomenological approach proposed by Alfred Schutz and assumptions of content analysis according to Bardin (1977). The data revealed that consumption appears as a way to improve the living conditions and "reward" the efforts undertaken through the work, whether formal or informal. It is noted including the difficulty to glimpse an ethical bias able to meet the need for actions to reduce the environmental impacts linked to production and consumption without the consumer feel sacrificed in the face of volatile insatiability of your requirements. Thus, the perceived still not realized fully in the lived of these women, because some obstacles still hinder effective and continuous participation.

Key words: Female, consumption, sustainability.

Este artigo tem como eixo norteador o tema consumo sustentável na perspectiva das mulheres que frequentam o Instituto Federal de Educação, Ciência e Tecnologia de Sergipe (IFS). O estudo faz parte dos constructos incididos na pesquisa de doutorado do Programa de Pós- Graduação em Desenvolvimento e Meio Ambiente da Universidade Federal de Sergipe (PRODEMA), cujas pesquisas possuem foco na Região Nordeste do Brasil, sendo desenvolvidas em formato de rede em parceria com as universidades federais dos Estados: Piauí (UFPI), Ceará (UFC), Rio Grande do Norte (UFRN), Paraíba (UFPB), Pernambuco (UFPE), Sergipe (UFS) e Bahia (UESC- Santa Cruz).

$\mathrm{O}$ estudo caracteriza-se como uma pesquisa explicativa qualitativa e quantitativa na qual a abordagem fenomenológica proposta por Alfred 
Schutz apresenta-se como a mais adequada, considerando a valorização da situação biográfica das pessoas, a relevância motivacional que governa seus interesses e a importância da construção do conhecimento diluído no cotidiano uma vez que "[...] do ponto de vista da Fenomenologia, a resposta deve ser procurada nas intenções e orientações desses indivíduos, guiados por seu conhecimento daquelas esferas da vida social relevantes para sua própria existência" (WAGNER, 1979, p.32).

A escolha do IFS como cenário do estudo surgiu da oportunidade de contato com grupos amostrais heterogêneos, ambos foco de políticas públicas direcionadas a exemplo das participantes do Programa Mulheres Mil (amostra "A") e as servidoras da instituição - professoras e TAEs- técnicas administrativas em educação (Amostra "B").

Neste contexto foi possível refletir sobre o espaço para as preocupações ambientais na agenda de consumo das mulheres. Por conseguinte a pesquisa apresenta em que parte destes itinerários a condição de ser mulher independente de renda e instrução as tornam semelhantes em suas decisões de consumo.

Tais questões trazem no bojo posicionamentos éticos construídos nas relações de poder em que estão inseridas. A autopercepção dos sujeitos como agentes de mudanças está relacionada com sua identidade e com a construção da responsabilidade em relação à apropriação dos recursos, ao cosmos de preocupações e olhares sobre as questões ambientais, fato este que se apresenta de forma diferenciada entre participantes das amostras " $\mathrm{A}$ " e "B".

Foram realizadas pesquisas no Estado de Sergipe, nos campi localizados nas cidades de Lagarto (Centro Sul), Itabaiana (Agreste Central), Estância (Sul), São Cristóvão, Reitoria, Aracaju (Grande Aracaju) e Nossa Senhora da Glória (Alto Sertão Sergipano).

O universo da pesquisa foi composto por amostras "A" e "B", sendo que participaram da pesquisa 233 mulheres, dentre elas 174 participantes do Programa Mulheres Mil e 59 servidoras (professoras e TAEs) distribuídas nas amostras "A" e "B".

O grupo "A" tem como traço principal a situação de vulnerabilidade econômica ou social, baixa instrução e perfil heterogêneo (trabalhadoras ru- 
rais, donas de casa, trabalhadoras informais, artesãs entre outras), uma vez que o Programa configura-se como uma política pública de empoderamento destinada às mulheres. O grupo "B" é formado por mulheres servidoras e professoras da rede federal de ensino. As amostras podem ser consideradas probabilísticas uma vez que refere-se a "[...] subgrupo da população no qual todos os elementos possuem a mesma possibilidade de serem escolhidos" (SAMPIERI, et al, 2006, p.254).

Pretendeu-se desta forma obter grupos amostrais heterogêneos que pudessem oferecer possibilidades de análises férteis e comparativas por meio da triangulação de dados, estabelecendo conexões e possibilidades de análises entre os grupos amostras e os dados coletados.

Com vistas a encontrar o quantitativo necessário para compor as amostras (o " $n$ " amostral) optou-se pelo método estatístico proposto por Barbetta (1999), por este ser direcionado às pesquisas das Ciências Sociais e considerar a variância de proporção nos subgrupos (campi) que compõem as amostras "A" e "B". Foram feitos cálculos para encontrar o "n" amostral necessário para todos os campi (composto de servidoras, professoras e participantes do Programa Mulheres Mil).

Como instrumentos de coleta de dados foram utilizados questionários diferenciados para as amostras "A" e "B". A aplicação dos instrumentos de coleta de dados ocorreu em momentos distintos considerando a necessidade de pessoal de apoio para aplicação dos questionários junto às participantes do Programa Mulheres Mil, uma vez que algumas mulheres não eram alfabetizadas ou possuíam dificuldade de leitura e escrita.

\section{Consumo, instância pré-paradigmática}

Pesquisas semeadas nos terrenos férteis das questões sobre consumo avançam nas reflexões acerca das polaridades que geralmente circundam o tema. Todos os dias nos deparamos com algumas delas, no limite entre a escassez e o excesso, o sustentável e o insustentável encontram-se processos em curso e descobertas. 
$\mathrm{Na}$ perspectiva de superar estas dicotomias, pesquisadores ligados à sociologia e antropologia do consumo indicam que se pode observar as práticas de consumo não somente pelo viés-econômico, mas também como prática produtora de "[...] cosmologias e sociabilidades na sociedade contemporânea" (BARBOSA, PORTILHO, VELOSO, 2009, p.11), como ponto de inter-relação por exemplo para discussões sobre problemáticas ambientais.

McCracken e Rocha (2003) indicam o aspecto positivo do interesse da academia no âmbito dos estudos sobre consumo, uma vez que por muito tempo foram negligenciados. Os autores indicam ainda a condição deste campo de estudo "pré-paradigmático", considerando que "[...] a história do consumo não tem história, não tem uma comunidade nem tampouco uma tradição acadêmica. É, nas palavras de T.S. Kuhn, "pré-paradigmática”. Ou, talvez seria mais acurado dizer, é 'recém-nascida' (Ibidem, 2003, p. 50).

Corroborando Canclini argumenta que "[...] há teorias literárias sobre a recepção e teorias estéticas sobre a fortuna crítica das obras artísticas. Mas não existe uma teoria sociocultural do consumo" (2008, p.60).

Assim, as pesquisas interdisciplinares constituem painéis "[...] com dois ou mais grupos ou núcleos principais isolados com peças encaixadas inteiramente, mas separados entre si por zonas de incertezas ou de desencaixe [...]" (VASCONCELOS, 2002, p. 172). O que converge com a proposição de Bauman, uma vez que estes processos de "diluição" atingem a tudo e a todos: o tempo, o espaço e a forma como os seres humanos interagem com os bens, seu próprio corpo, com os outros seres e o meio ambiente. A rapidez, a descartabilidade, o sentimento de "desencaixe" e a insaciabilidade tornaram-se latentes considerando que antigos modelos generalistas já não correspondem aos contextos de complexidade.

Neste contexto, a antropóloga social Lívia Barbosa ao apresentar o Livro de Daniel Miller intitulado "Teoria das Compras" (2002, p.16) adverte para os riscos da mesmice teórica em relação aos estudos do consumo, uma vez que boa parte dos estudos limita-se a considerar o consumo como ação constitutiva e fundamental para o processo de construção da identidade ou 
consideram o consumo como apenas compra de signos e não de mercadorias. Ações de consumo não perdem seu caráter utilitário, subjetivo e relacional, pelo contrário, faz-se necessário abrir novas portas que através da interdisciplinaridade possam conduzir a novos estudos e análises.

A obra "A ética romântica e o espírito do consumismo moderno" de Colin Campbell (2001) representa um expoente nas reflexões sobre consumo, uma vez que para o autor não há nenhuma teoria satisfatória (corroborada) que possa subsidiar estudos de consumo moderno. Campell indica aspectos emergentes que devem ser considerados na construção de novos referenciais sobre as práticas de consumo:

Primeiro, porque foi necessário provar que uma teoria do comportamento do consumidor moderno era necessária; segundo, porque nem a economia clássica nem Veblen haviam fornecido uma [teoria] que se mostrasse apropriada; terceiro, porque uma teoria hedonística da atividade social é fundamentalmente distinta daquelas de base utilitária comumente materializadas na economia; e quarto, porque uma teoria do moderno comportamento hedonístico, na verdade pode explicar os aspectos característicos do comportamento do consumidor moderno (CAMPBELL, 2001, p. 17).

Já para Miller (2012) existe uma grande barreira na qual a maioria das pessoas tem dificuldade de observar as próprias formas de consumo narcisista, sendo mais "fácil" reconhecer o que seria supérfluo nas práticas de consumo alheias, inclusive nos estudos acadêmicos.

Campbell (2001) esclarece que as abordagens pautadas na moralização a respeito das práticas de consumo podem desprezar outros aspectos importantes nos estudos relacionados ao consumo. Mesmo quando a pesquisa refere-se à ética relacionada às relações de consumo e seus desdobramentos (consumo ativista, ético, verde, consciente entre outros), faz-se necessário estudos mais aprofundados não somente quanto aos efeitos, mais principalmente sobre os papéis e motivações de seus agentes. 
Tais posicionamentos tornaram ainda mais urgente o chamado à interdisciplinaridade, considerando que lacunas disciplinares foram se formando tornando cada vez mais complexos os estudos relacionados ao consumo pois:

Mais importante que a quantidade de trabalhos é a relevância teórica que a categoria consumo passou a ter em algumas disciplinas e a atribuição da classificação consumo a áreas e domínios que antes não eram percebidos como tal e nos quais sua eventual presença era inteiramente desqualificada - como, por exemplo, no caso da cidadania, da cultura, da política, do meio ambiente e da religião (BARBOSA; CAMPBELL, 2006, p.23)

Neste contexto se ampliaram os estudos sobre consumo, consumismo, cultura do consumo, sociedade de consumo dentre outros relacionados às novas dinâmicas da sociedade. Para Guerra (2011), estas mudanças no campo acadêmico surgiram do entendimento de práticas de consumo como processos de reprodução social e observação da sociedade contemporânea como sociedade de consumo uma vez que a "[...] disseminação dos pressupostos teóricos da centralidade do consumo na sociedade moderna, caracterizando-a como sociedade de consumo, surgiu uma nova produção acadêmica, constituída a partir de outro olhar sobre o fenômeno" (2011, p.15).

Este artigo corrobora com a proposta de Bauman, na qual aspectos da chamada "modernidade líquida" ganham espaço antes ocupado pela sociedade "[...] sólido-moderna de produtores - uma sociedade, permitam-me repetir, que apostava na prudência e na circunspecção a longo prazo, na durabilidade e na segurança [...]” (Ibidem, 2008b, p.44).

Para Bauman (2008, p. 20) na sociedade de consumo a construção das subjetividades dos consumidores seria pautada em escolhas de compra, como a materialização da verdade interior "objetificadas". Para o autor, as mercadorias são acompanhadas de respostas para os problemas dos consumidores, que muitas vezes "tomam ciência do problema" quando são motivados por exercícios de comparação. 
Segundo Botsman e Rogers (2011, p.18) “[...] o que nos interessa mais não é o status de luxo ou o lado elitista do consumo conspícuo que Veblen mencionou, mas sim, o excesso de consumo de massa voraz que começou na década de 1920 e explodiu em meados da década de 1950". Atualmente os bens posicionais não precisam ser necessariamente caros, podem fazer parte de sistemas simbólicos que lhe atribuem grande valor, ou apresentarem certa instabilidade de acordo com o grau de escassez e valorização no mercado. Em consonância Campbell (2001) sinaliza que os aspectos invisíveis e conspícuos do consumo não necessitam de pressupostos ligados ao status e ao prestígio, embora confirme o grande poder de influência destes âmbitos.

O desfrute imaginativo de produtos e serviços é uma parte crucial do consumismo contemporâneo se revela pelo importante lugar ocupado, na nossa cultura, mais pelas representações dos produtos do que pelos próprios produtos. Isso não só abrange abertamente os anúncios e catálogos comerciais, como as revistas, periódicos, cartazes, cartões, calendários e até obras de arte. Em muitas destas, a fronteira entre a representação dos interesses de determinado fabricante e distribuidor e as imagens produzidas primeiramente para entretenimento é claramente distinguível, sugerindo que as duas coisas preenchem a mesma função de facilitar o hedonismo imaginativo (CAMPBELL, 2001, p.134).

Deve-se, portanto, considerar que a áurea em torno da oferta de produtos envolve conceitos econômicos do que chamamos "utilidade", uma vez que os produtos são adquiridos não somente pelo status ou simbolismo, mas para auxiliar em necessidades cotidianas. Considera-se que bens econômicos são úteis e escassos, aos quais a utilidade surge como um juízo de valor. Assim, quanto mais escasso for um bem, maior valor este terá, o que por vezes parece paradoxal, se considerarmos que um diamante tem mais valor que a água, mesmo que esta seja essencial para a vida. 
A criação de grande variedade de produtos e serviços aliada a obsolescência programada, a influência da moda e suas constantes variâncias colaboram para que o próprio consumidor observe-se como inadequado e antiquado motivando-se em busca de produtos e serviços que possam inseri-lo em uma perspectiva atualizada perante as tendências.

As necessidades dos consumidores seriam ilimitadas e insaciáveis convergentes com duas proposições básicas, a primeira como "[...] conseqüência da sofisticação, do refinamento, da personalização dos desejos e necessidades das pessoas. A segunda, como uma exigência do sistema capitalista para a sua própria sobrevivência" (BARBOSA, 2008, p.34). Não se pode negar a motivação das pessoas em procurar prazer por meio das práticas de consumo.

O prazer é procurado por meio de estimulação emocional e não meramente sensorial, enquanto, em segundo as imagens que preenchem essa função são ora criadas imaginativamente, ora modificadas pelo indivíduo para o autoconsumo, havendo pouca confiança na presença dos estímulos "reais". Esses dois fatos indicam que o hedonismo moderno tende a ser encoberto e autoilusivo, isto é, os indivíduos empregam seus poderes imaginativos e criativos para construir imagens mentais que eles consomem pelo intrínseco prazer que elas proporcionam, uma prática que se descreve melhor como de devanear e fantasiar (CAMPELL, 2001, p. 115).

Desta forma um aspecto marcante das práticas de consumo moderno é a insaciabilidade. Uma necessidade de acordo com Solomon, (2011, p. 51) "[...] é um motivo biológico básico; um desejo representa um modo que a sociedade nos ensinou para satisfazer a necessidade".

A questão relativa ao que seria necessário e supérfluo também influi nestas dinâmicas lembrando que existe a tendência de julgamentos acerca do consumo alheio e dificuldade de reflexão sobre o consumo próprio de cada sujeito. 
Raramente temos uma visão clara de nossas próprias formas de narcisismo consumista, sobretudo no que diz respeito aos cidadãos educados das economias desenvolvidas - tais como a maior parte dos leitores deste livro [Darwin vai às compras]. Podemos sentir desprezo pelas formas de consumo supérfluo que julgamos grosseiras, extravagantes e surreais: botox, Hummers e as mansões de mau gosto dos novos ricos esteticamente perdidos. Ao mesmo tempo, classificamos nossas próprias variedades menos claras de narcisismo consumista como naturais, respeitáveis, e formas iluminadas de autêntica expressão, realizações merecidas e virtudes cívicas (MILLER, 2012, p. 86).

Pode-se afirmar que existem exercícios imaginativos de projeção de situações que o consumidor deseja alcançar, por meio da sensação de bem estar, da aceitação e valorização das outras pessoas e status quo. Desta forma, para Campbell (2001) a atividade fundamental do consumo não estaria centrada no processo de percepção da necessidade, escolha, compra, uso e descarte dos produtos, mas na procura do prazer imaginativo que a imagem do produto empresta como uma espécie de "hedonismo mentalístico".

Neste tocante, o presente estudo partilha da visão que muitas das motivações para o consumo advêm de processos de experimentação, percepção e construção de situações mentalísticas ideais que em ciclos de materialização e "reforço" seja por meio de aprovação social ou mesmo de sensações de prazer e satisfação que provocam anseios para repeti-los ou expandi-los.

Estes processos podem formar adesões individuais e coletivas às tendências. Desta forma uma peça de roupa, um sapato ou um enfeite para o cabelo (não importa se de grife ou não) comunicam a adesão à moda como podemos observar nas figuras 01 a 05. Tendências são lançadas, grupos de referência (a exemplo dos artistas) e publicidades divulgam e reforçam variedades de produtos que são adquiridos e ressignificados como "moda atual" no dia a dia. 


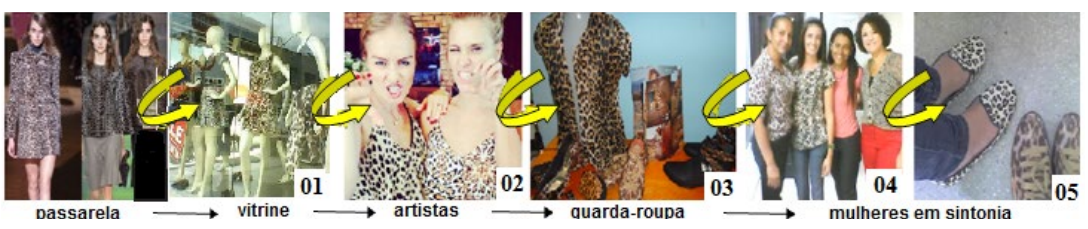

Figura 1. Lançamento de tendência de moda. Fonte: https://www. google.com.br/search? $\mathrm{q}=$ artistas+usam+print+animal\&esp. Acesso em: 06 mar. 2015.
Figura 2. Artistas divulgam visual print animal https:// Fontehttp://caras.uol.com.br/ fashion/angelica-e-carolinadieckmann-usam-animal-print -em-aniversario\#.VPnvL_nF9So. Acesso em: 06 mar. 2015.
Figura 3. Itens "print animal" encontrados no armário da pesquisadora. Fonte: arquivo pessoal, 2015.
Figuras 4 e 5 . Servidoras e suas blusas e sapatos da moda "print animal". Fonte: arquivo pessoal, 2015.

A frivolidade das tendências e a rapidez com que são substituídas podem potencializar o caráter ilimitado e insaciável dos desejos humanos, pois reside nesta situação uma das maiores problemáticas em relação à utilização de recursos naturais escassos e em relação a casos patológicos relativos ao consumismo (oneomania).

Ressalta-se inclusive que a sensação de aprovação social, de estar incluído, bem informado e conectado com as novidades são grandes motivações que alimentam o ciclo ininterrupto de compras, abrindo espaço para que a moda ganhe espaço no cotidiano das mulheres.

Todos os dias pode-se observar exemplos semelhantes no cotidiano das compras, que muitas vezes insere as pessoas neste ciclo sem que as mesmas se dêem conta deste processo, considerando a existência de eixos de complementaridade entre as práticas de consumo formando "estilos de vida" de acordo com novos cosmos de interesses.

Assim, o atributo da complementaridade pode ser pensado como uma estratégia das empresas para aumentar as vendas e também como um potencial fomentador do aumento de padrões e níveis de consumo.

Neste contexto de tantos artifícios subliminares torna-se difícil para o consumidor compreender o quanto estes aspectos podem desencadear efeitos negativos nos âmbitos psicológico, financeiro e ambiental. Desta forma torna-se desafiador para os movimentos em prol da sustentabilidade comu- 
nicar e promover a reflexão como o principal passo antes das decisões de compra.

\section{Consumo: uma questão ambiental}

Segundo Bauman (2007, p. 106) “[...] todos os seres humanos são e sempre foram consumidores, e nossa preocupação com o consumo não é novidade", uma vez que criar condições adequadas para subsistência foi à mola propulsora do desenvolvimento de variadas técnicas que proporcionaram ao homem reagir diante das adversidades, planejar e controlar a utilização dos recursos e principalmente modificar o meio ambiente em que vive.

Neste contexto, os aspectos negativos surgem da reivindicação cada vez maior de produtos e serviços advindos do "[...] intercâmbio, aquisição, consumo e estoque de recursos visando apenas aos próprios interesses, estabelecendo, por vezes, pesados encargos ao ecossistema" (GIACOMINI, 2008, p.14). O autor sinaliza ainda que:

Social e economicamente legítimo, o consumo quando distorcido, gera o consumismo, que por sua vez, tem origem nas pessoas, embora possa ser fortemente influenciado por políticas governamentais, empresas e grupos sociais. Trata-se de um mal que atinge os próprios consumidores, as relações sociais e o meio ambiente (Ibidem, 2008, p.21).

Segundo (BAUMAN, 2007, p.106), o “[...] advento da variedade líquida da modernidade" abriu espaço para que de forma eficiente, as práticas de consumo pudessem gerar inquietações de toda ordem em homens e mulheres contemporâneos.

Zygmunt Bauman no livro Modernidade Líquida apresenta este termo como um processo de mudanças globais, no qual vários âmbitos como as relações sociais e afetivas, o consumo e o trabalho sofrem rupturas tornandose fluídos, flexíveis e instáveis. Para Bauman “[...] a modernidade [líquida] começa quando tempo e espaço são separados da prática da vida e entre si, 
e assim podem ser teorizados como categorias distintas e mutuamente independentes da estratégia e da ação" (Ibidem, 2001, p.15). O autor completa ainda que:

Não se ganha muito com considerações de "longo prazo". Se a modernidade sólida punha a duração eterna como principal motivo e princípio da ação, a modernidade "fluída" não tem função para a duração eterna. O "curto prazo" substituiu o "longo prazo" e fez da instantaneidade seu ideal último" (Ibidem, 2001, p. 145).

Todos os dias milhões de pessoas relacionam-se com variadas práticas de consumo que lhes conferem a oportunidade de saciar várias necessidades ao mesmo tempo. Estas práticas têm como base a: apropriação, mediação, habilitação, acesso e uso.

Apropriação de recursos, espaços, imagens e aspectos simbólicos materiais e imateriais; mediação de relações, informações e construção de conhecimento; habilitação, no sentido de capacitar-se aos novos hábitos, adequação à tecnologia e processos civilizatórios; acesso ao consumo intangível, codificação e virtualização dos espaços; atribuição de novas formas de uso a produtos e serviços (SIQUEIRA, 2012, p. 25)

Destes processos decorrem variadas problemáticas ambientais considerando que a disponibilidade de recursos não ocorre de forma equitativa ao redor do mundo. Formam-se então quadros de desigualdade estrutural nos quais muitas pessoas não possuem acesso a itens básicos para sua subsistência (subconsumo), enquanto outros, com “apetite insaciável” praticam hábitos de consumo insustentáveis (hiperconsumo), cujo ônus socioambiental é compartilhado de forma coletiva, como o aumento das emissões de $\mathrm{CO} 2$ e geração de resíduos fomentada pela obsolescência programada. 


\section{Mulheres no contexto de problemáticas ambientais}

A ampliação do debate sobre as problemáticas ambientais caminhou juntamente com a luta de grupos sociais em prol da valorização de direitos, a exemplo dos esforços de mulheres que vislumbraram a latente necessidade de construção de novos discursos e espaços de ação que pudessem representar a luta por direitos na esfera pública e valorização da mulher como cidadã.

Através da nova cultura do trabalho, as mulheres exprimem a vontade de conquistar uma identidade profissional por direito próprio e mais abrangente, o desejo de serem reconhecidas a partir daquilo que fazem e já não do que são 'por natureza', enquanto mulheres. O ciclo do pós-dona-de-casa fez entrar o feminino no universo concorrencional e meritocrático tradicionalmente masculino (LIPOVETSKY, 1997, p.219).

Para Leff "[...] se o conhecimento do mundo aparece como uma construção masculina, seria necessária uma desconstrução feminista” (2006, p. 329). Neste contexto, o Ecofeminismo surge como proposta de conexão entre as questões relacionadas à mulher e ao meio ambiente, apresentando-se como uma nova vertente do movimento Feminista, cujo termo foi criado em 1974 por Françoise d'Eaubonne.

O movimento surgiu da percepção de que a opressão feminina relacionava-se com diversos problemas socioambientais, e que mudanças neste sentido poderiam promover benefícios às mulheres, suas famílias e ao meio ambiente, considerando a ressalva de não buscar desnaturalizar seus papéis, mas de valorizar as especificidades e diferenças biológicas como vínculo de ligação com a natureza. Torna-se mais clara a observação dos desafios a superar de modo que as ações voltadas à sustentabilidade possam ser convergentes e coerentes com as realidades das comunidades uma vez que não existe uma crise ambiental única.

Em países democráticos como o Brasil, a participação e o poder de escolha são proclamados como alguns dos principais meios de ação do cidadão 
perante as problemáticas, contudo, por vezes o (a) próprio (a) cidadão (a) desconhece qual o seu real papel nestas dinâmicas, o que ocorre também nas esferas relacionadas ao consumo. Observa-se que cada vez mais a mulher é valorizada pela sua condição de consumidora, isto é, pelo seu poder de decisão e aquisição.

Os anúncios publicitários anunciam a inserção da mulher no trabalho, a ampliação do poder de decisão sobre sua própria vida, sexualidade e escolhas no lar, na tutela do consumo de entes da família e principalmente, como agente de transformações, sociais, econômicas, culturais e ambientais. Desta forma, a mulher está inserida em contextos de grande responsabilização no exercício de seus papéis sociais.

Para as empresas o cosmo feminino torna-se um campo ilimitado de oportunidades de negócios criando estratégias cada vez mais atraentes, uma vez que a beleza, a jovialidade, a sensualidade e feminilidade são aspectos muito valorizados.

Coot sinaliza que no século XIX o estilo de vida americano teve grande influência na construção de novas representações e imagens das mulheres, imagem esta que começa a "[...] ser vendida com a urbanidade e o esplendor material da produção em série da nova era" (1991, p. 98).

A partir destas dinâmicas foi possível estabelecer o elo do qual a mulher é até hoje o foco da maioria das estratégias de marketing que buscam fomentar o consumo como expressão de liberdade e poder de escolha, pois “[...] os publicitários apressaram-se a embalar a individualidade e a modernidade das mulheres sob forma de mercadoria [...] conseguiram sobrepor símbolos modernos às prioridades tradicionais das mulheres" (COOT, 1991, p.110), tornando a fronteira entre o empoderamento e poder de compra cada vez mais tênue.

Nesta trajetória, é crescente o movimento de mulheres que avançam obstinadamente na apreensão de estéticas e modelos socialmente construídos pelo aporte das imagens midiáticas e publicitárias, por reconhecerem no consumo a expressão e gozo de suas conquistas e autonomia, enquanto outras ainda carregam o estigma da pobreza e da falta de oportunidades geracionais. 
Germaine Greer, autora de livros marcantes como "A mulher eunuco" e "A mulher inteira" alude a este contexto, pois "[...] sendo o feminismo incompatível com o consumismo, o marketing cooptou-o como uma moda, e logo em seguida declarou-o passado, só para cooptá-lo repetidas vezes sob diferentes rótulos estilísticos" (2001, p.18). Esta perspectiva considera o consumismo como a apreensão do volúvel e supérfluo em detrimento da reflexão na ocasião das escolhas. Já para Bauman "[...] o que caracteriza o consumismo não é acumular bens (quem faz deve ser preparado para suportar malas pesadas e casas atulhadas), mas usá-los e descartá-los em seguida a fim de abrir espaço para outros bens e usos" (2004, p.67).

Diante do exposto pode-se notar o quão conflituosa é a relação entre a mulher, o consumo e o desafio da sustentabilidade, o que nos permite questionar se as mulheres configuram-se como agentes que colaboram com práticas de consumo sustentáveis ou contribuem para o aumento de padrões de níveis de consumo.

\section{A presença das mulheres no IFS}

\section{Participantes do Programa Mulheres Mil, a rede de Institutos Federais e o convite à inclusão}

O Programa Mulheres mil foi instituído pela portaria ministerial $n^{\circ}$ 1.015 de 21 de julho de 2011, com apoio da Secretaria de Educação Profissional e Tecnológica do Ministério da Educação (SETEC), dos Institutos Federais de Educação, Ciência e Tecnologia (IFS). Trata-se de um "convite" para que as mulheres em situação de vulnerabilidade possam retornar à escola de forma diferenciada (ensino pautado na metodologia de "acesso, permanência e êxito).

Este "convite" pode ser considerado uma oportunidade de participação em cursos e apoio à geração de renda, além da troca de experiências e saberes que possam promover o desenvolvimento pessoal, familiar e comunitário partindo-se da valorização dos itinerários formativos das mulheres participantes. $\mathrm{O}$ acesso inclusivo representa a oportunidade para que as mu- 
lheres em condição de defasagem escolar possam participar das atividades do programa, além de estabelecer novas sociabilidades e diálogos entre o conhecimento acadêmico e os saberes comunitários.

O programa está inserido no conjunto de políticas públicas para melhoria da qualidade de vida das mulheres e suas comunidades, centrado em três eixos básicos: educação, cidadania e desenvolvimento sustentável. No início de 2014, o Ministério do Desenvolvimento Social e Combate à Fome (MDS) e o Ministério da Educação (MEC) inseriram o programa no âmbito do Programa Nacional de Acesso ao Ensino Técnico e Emprego no âmbito do Plano Brasil Sem Miséria (Pronatec/BSM), com vistas a investir na qualificação das mulheres participantes do programa inclusive as beneficiárias do Programa Bolsa Família.

Percebe-se assim que a trajetória de empoderamento destas mulheres transcende o aporte dos Programas de transferência de renda e adentra ao âmbito de outros aspectos importantes como educação, espaços de ação e abertura para o diálogo.

\section{Mulheres professoras e técnicas administrativas em Educação (TAEs)}

Escrever sobre a presença das mulheres em uma Instituição Pública Federal não é tarefa fácil, mesmo considerando o tema como transversal aos objetivos deste estudo. Para tanto fez-se necessário avançar no entendimento de que as pessoas " [...] constituem o princípio essencial de suas dinâmi$\mathrm{ca}$, conferem vitalidade às atividades e processos, inovam, criam, recriam contextos e situações [...]" (VERGARA, DAVEL, et al. 2009, p.31). Neste contexto Bergue (2005, p. 69) sinaliza a divergência entre o informal e o formal chamando-se este de "inconsistência burocrática" na qual o indivíduo apresenta dissonâncias entre o "comportamento formal e a conduta real" o que para o objeto de estudo desta pesquisa significa que o indivíduo pode ser motivado a agir em prol do consumo sustentável em determinado ambiente por imposição do dever, mas na realidade não estar sensibilizado a cerca dos benefícios de sua ação, vindo a abandoná-la assim que tiver oportunidade.

Assim, torna-se necessário valorizar contextos ambivalentes que po- 
dem combinar "[...] exterioridade e objetividade com as sutilezas e sensibilidades subjetivas, para serem capazes de lidar com os aspectos relacionais e intrínsecos à natureza humana no âmbito do trabalho e da subjetividade organizacional" (VERGARA, DAVEL, et al. 2009, p.33), considerando que segundo os autores supracitados (ibidem, et al. 2009, p.33) é importante perceber que cada sujeito na instituição:

a) Tem seu espaço interior, que ele (a) percebe como completamente seu;

b) Que esse espaço relaciona-se com a exterioridade;

c) Que ele é historicamente construído;

d) Que é decisivo nas escolhas das pessoas durante sua vida;

e) Que acaba por provocar mudanças no entorno.

A mulher investida em cargo público também ressignifica suas práticas e o entorno, inclusive seu lócus de trabalho como pode-se observar nas figuras 06 a 08:

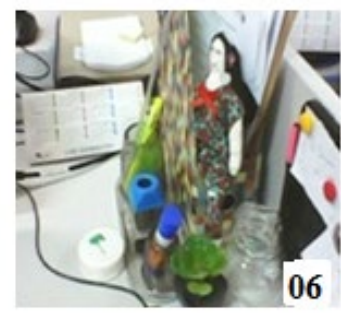

Figura 06 - Locus de trabalho de professora (Reitoria). Fonte: Siqueira, 2015.

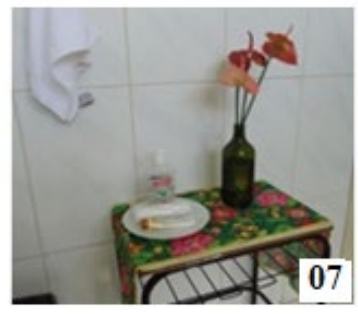

Figura 07 -Organização de banheiro (antigo prédio do Campus Estância. Fonte: Siqueira, 2013.

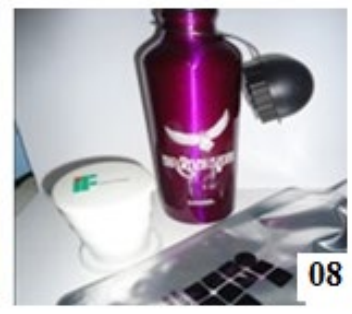

Figura 08 - Iniciativas do IFS para reduzir consumo de copos descartáveis. Fonte: Siqueira, 2015 .

Deve-se lembrar que as participantes da amostra "B" (servidoras públicas) por ocuparem cargo público são subordinadas a um código de ética específico que estende o perfil comportamental "ético" relacionado ao cargo à vida pessoal. Nota-se assim, a tênue inter-relação entre o sujeito que influência os processos da organização e o processo contrário do qual a or- 
ganização é capaz de influenciar o "querer" e aludir ao "dever" dos sujeitos por meios de normativas e regulamentos a exemplo do Código de Ética do Serviço Público.

Com vistas a subsidiar a reflexão a respeito do posicionamento ético advindo do empoderamento e responsabilidade que emana das práticas de consumo das mulheres, foram eleitos autores como Schudson (2001), Lipovetsky (2005) e Hans Jonas (2006), lembrando que o tema surge no estudo de forma transversal.

Segundo Lipovetsky (2005) vivem-se tempos de “éticas razoáveis" nas quais pessoas, empresas e instituições diversas tentam equilibrar aspirações individuais à complexidade das problemáticas da coletividade uma vez que "[...] as injunções formais ao dever estão carcomidas, logo é o momento de exaltar a responsabilidade sem fronteiras, ecológica, bioética, humanitária, econômica ou midiática". São tantas fragmentações que o sentido de uma ética coletiva parece ultrapassado por dezenas de versões de éticas "indolores" como adverte Lipovetsky:

Se, de um lado, os chamamentos à responsabilidade não podem ser desvinculados da ideia de dever moral, de outro, tem isso de específico: em parte alguma conclamam a auto-renúncia sobre o altar dos ideais superiores. Nossa ética de responsabilidade é uma ética "razoável", inspirada não na imposição do desprendimento em relação aos fins pessoais, mas um esforço de harmonização dos valores com as conveniências particulares, de harmonização do princípio dos direitos individuais com as coerções da vida social, econômica e científica. O intento é tão somente compensar a ampliação da lógica individualista pela legitimação de novas obrigações coletivas, visando à obtenção de um ponto de equilíbrio entre o dia de hoje e o de amanhã, entre o bem-estar individual e a proteção ao meio ambiente, entre o progresso científico e o humanismo, entre o direito de pesquisa e os direitos humanos, entre os imperativos científicos e os direitos dos animais, entre a liberdade de imprensa e o respeito ao 
direito das pessoas, entre a eficácia e a justiça. Não é, em nenhuma hipótese, a cultura heróica da abnegação pessoal que reassume o papel central; a responsabilidade pós-moralista é o dever desonerado da noção de sacrifício (LIPOVETSKY, 2005, p. 186).

Nota-se que este debate provoca controvérsias entre os defensores de “éticas razoáveis" relacionadas ao consumo e aqueles consonantes as medidas limitativas, uma vez que o sentido de advertência, redução e/ou restrição relativas às práticas de consumo insere a perspectiva de balizamento entre o que é considerado menos ou mais impactante e a motivação dos sujeitos em colaborar.

Podem-se ainda conceber posturas pós-moralistas (postmoralist), nas quais segundo Schudson (2001) posições baseadas em críticas, em perfis julgadores e intolerantes em si mesmos não oferecem subsídios em busca de soluções.

Nas próximas décadas a noção de abstinência, racionamento e sacrifícios de ações no âmbito individual serão intensificados considerando o panorama atual de exaustão dos recursos naturais e inobservância da capacidade de resiliência dos ecossistemas.

Hans Jonas em sua obra $O$ princípio responsabilidade: ensaio de uma ética para civilização tecnológica postula um pertinente e imperativo chamado ao querer-dever e ao agir, posto que o tempo urge:

A ética da responsabilidade se reveste aqui da prerrogativa de caminhar em direção ao 'dever-agir' elegendo como imperativo fundamental o dever de tomar para si a responsabilidade pelo que ainda está por vir; tal é expresso na fórmula: Age de tal forma que as consequências de tua ação não interrompam a possibilidade de a vida continuar se manifestando em todas as suas expressões como hoje nós a percebemos (JONAS, 2006, p.47 In. FONSÊCA, 2014, p. 131).

Cremos que esse 'imperativo' da ponderação e do cuidado é de fato algo que se nos impõe inexoravelmente, pois não há outro caminho 
capaz de nos comover -pois o temor é um sentimento- senão pela ligação do temor com o amor em vista dos acontecimentos reais que presenciamos na contemporaneidade. Se a tarefa concreta é dar freios, ao mesmo tempo é oferecer alternativas - daí o tempo do desenvolvimento sustentável e justo, mote da luta ecológica hoje. Não obstante, para isso funcionar, dependemos da consciência e da sensibilidade, da reconversão do sujeito à sua essência inter-humana ao mesmo tempo em que filho da natureza. São esses elementos que podem construir outro agir. Vai-se da informação à emoção e à ação.

Daí que a proposta da ética da responsabilidade é se apresentar como uma força pedagógica e afirmativa que, através do suscitar freios voluntários e fazer o arquétipo do amor, reeduca os desejos de crescimento material limitado e os processos de objetivação a que somos levados na velocidade do capitalismo. (FONSÊCA, 2014, p.74).

Assim duas palavras são consideradas chaves para o entendimento da responsabilidade em Hans Jonas, concebida como princípio ético e como sentimento perante o presente e as futuras gerações.

\section{Resultados e discussões: mulheres consonâncias e dissonâncias}

As mulheres e suas práticas de consumo por vezes passam pelo crivo do senso comum como agentes de consumo desenfreado e fútil.

Uma das questões norteadoras desde estudo alude a existência de diferentes cosmos de interesse no cotidiano das mulheres, assim pode-se perguntar se as variáveis como renda, nível de escolaridade e espaços de ação podem influenciar práticas de consumo ou existe algum aspecto que represente similitudes independentes destas variáveis? De fato, após análises percebe-se que tais variáveis influenciam a forma como as mulheres se autopercebem, a geração de renda, o acesso ao trabalho, ao ensino formal, à informação, aos hábitos e práticas de consumo inclusive o lazer e a gestão do tempo. Embora se percebam aspectos em comum entre as mulheres das amostras "A" e "B". 
$\mathrm{Na}$ trajetória deste estudo observamos que a família constituída em seus lares por filhos, esposo ou familiares e o trabalho são focos centrais dos discursos, tanto pela preocupação com proveito de renda, a tutela de consumo, escolaridade, gestão do tempo e as relações com trabalho formal e informal povoam os cosmos das mulheres participantes do estudo.

Sentem a pressão em relação ao tempo, aspectos estéticos e tecnológicos e a valorização do consumo hedonista ligado ao bem estar, aos atributos de feminilidade e poder de escolha (você quer, você merece, você pode) em contraponto ao desafio de consumir de forma mais sustentável.

As mulheres mil (amostra "A") apresentaram maior dificuldade em autorefletirem acerca de suas qualidades, neste contexto citaram qualidades pessoais ligadas ao amor, cuidado e carinho. Em relação às preocupações as mulheres citaram os filhos e familiares (43,10\%), segurança, violência e marginalidade (15,52\%), e saúde (12,06\%). Estes três aspectos foram consonantes as citações das professoras e servidoras do IFS (amostra "B"). No tocante a autopercepção as servidoras do IFS tiveram maior desenvoltura em falar de si mesmas indicando como maiores qualidades aspectos ligados ao trabalho, persistência e determinação.

Goidanich complementa que "[...] isto significa que ao mesmo tempo em que carregam o peso da cultura e da sociedade sobre seus diferentes papéis, são capazes em alguma medida, de determinarem a si mesmas" (2012, p.26), podendo neste processo gerar mudanças positivas em seu entorno.

Observa-se convergência também em relação a alguns sonhos de consumo que incluem casas, filhos e a vontade de simplesmente "ser feliz" dentre outros sonhos. Quando questionadas acerca do que gostariam de mudar em si mesmas os aspectos relacionados de mudanças estéticas e questões de beleza foram citadas por $32,18 \%$ das mulheres mil e por apenas $6,77 \%$ das professoras e TAEs, o que podem fazer inter-relação com baixa estima e acolhida a padrões estéticos e influências externas de grupos de referências apresentados na mídia e em suas comunidades, considerando que as mulheres das duas amostras afirmaram ter conhecimento das novidades através de anúncios, pela televisão, revistas, catálogos e por meio de outras pessoas. 
Na perspectiva das despesas nota-se novamente que as mulheres buscam atender em primeiro lugar as demandas do lar, independente de terem ou não renda própria. Gastos com alimentos, água, energia, roupas e sapatos foram citados por mulheres de ambas as amostras como os mais representativos. Neste tocante vale salientar que as professoras e TAEs por terem a "segurança" de um emprego formal com certa estabilidade citaram investimentos em educação (dela própria e de familiares), plano de saúde, opções de lazer (cinema, bares, shows, teatro), viagens e presentes.

As consonâncias apresentam os aspectos comuns às mulheres das duas amostras, já as dissonâncias apresentam os aspectos diferenciados.

No contexto das participantes do Programa Mulheres Mil observa-se um viés mais voltado ao lar (materiais de construção e móveis) e a aquisição de roupas, sapatos e itens para os filhos, considerando que ainda é reduzido o número de mulheres que podem matricular os filhos em escolas particulares e que possam dispor de plano de saúde (salvo como dependentes do esposo). Torna-se assim mais agravante a carência de creches, o acesso aos serviços do Sistema Único de Saúde (SUS), de opções de escolas com ensino de qualidade e opções de lazer, para a população que não possui outras opções além do que é oferecido pelos órgãos governamentais (município, estado e governo federal).

Nota-se assim que o sentido de qualidade de vida atrelado à cidadania permanece frágil na oferta de condições básicas para que a população possa usufruir de condições de desenvolvimento igualitárias.

Qual seria um limiar adequado do ponto de vista da sustentabilidade no cotidiano destas mulheres em seus diferentes contextos diários?

Diante dos diferentes contextos influenciados pelos estratos de renda, nível de escolaridade, cultura e acesso ao trabalho não se pode "estabelecer" uma "cesta-sustentável", mas indicar possíveis caminhos nos quais a preocupação ambiental deve ser considerada relevante e presente no processo de escolha e decisão de produtos e serviços. Mulheres com menor ou maior renda podem buscar "táticas" diárias que produzem efeitos não somente financeiros, mas também ambientais, visto que o consumo sustentável perpassa pela gestão eficiente dos ambos os recursos. 
O conjunto de propostas indicado no Manual Consumo Sustentável (BRASIL, 2005, p.18) oferece seis tópicos importantes que constitui caminhos possíveis para práticas sustentáveis, considerando esforços de autopercepção e motivação dos sujeitos em prol de mudanças.

1. Deve ser parte de um estilo de vida sustentável em uma sociedade sustentável;

2. Deve contribuir para nossa capacidade de aprimoramento, enquanto indivíduo e sociedade;

3. Requer justiça no acesso ao capital natural, econômico e social para as presentes e futuras gerações;

4. O consumo material deve se tornar cada vez menos importante em relação a outros componentes da felicidade e da qualidade de vida;

5. Deve ser consistente com a conservação e melhoria do ambiente natural;

6. Deve acarretar um processo de aprendizagem, criatividade e adaptação.

Para tanto o conhecimento das receitas e despesas, a autoperceção das ações pessoais e do entorno, o acesso à informação e o poder de influenciar positivamente mediante exemplos são essenciais.

O acesso à informação é uma variável importante para a ampliação do diálogo e do fortalecimento da mulher como agente de mudanças, considerando a oportunidade de conhecer aspectos importantes sobre direitos, deveres e principalmente estabelecer conexões entre as causas dos problemas socioambientais que parecem distantes, mas cujos ônus atingem a todos.

\section{Considerações Finais}

Concernente aos limites da pesquisa, a investigação que indica que as mulheres tendem a aumentar e ressignificar padrões e níveis de consumo, uma vez que a tutela das práticas de consumo surge como prioridade frente às problemáticas ambientais.

Os dados sinalizam esferas distintas de práticas de consumo, construídas mediante diferentes itinerários formativos, nas quais pode-se perceber a influência da percepção que as mulheres têm de si mesmas, da geração de 
renda, do nível de escolaridade, organização das rotinas em torno do lar e do trabalho (seja ele formal ou informal).

A condição sociocultural "de ser mulher" investida em papéis sociais e biológicos ligados a construção da identidade estabelecem "elos de ligação" que tornam convergentes algumas percepções e práticas de consumo. Significa dizer que existem cosmos de interesses comuns às mulheres independentes dos estratos de renda, nível de escolaridade e acesso ao trabalho como disposto no quadro 01.

Este artigo corrobora com o sentido de coabitação de papéis antigos e modernos no cotidiano das mulheres contemporâneas. Neste processo de empoderamento, reflexão e reinvenção, pode-se observar a valorização do diálogo e da mulher como agente de mudanças, capaz de mobilizar e ressignificar o próprio processo, o entorno, influenciar entes e instituições envolvidas.

Diante de variadas limitações, as mulheres de ambas as amostras buscam nas "táticas" cotidianas, formas de ressignificar as opções de consumo, o que pode representar escolhas e práticas mais sustentáveis (ligadas à economia dos recursos, redução de padrões e níveis de consumo) ou não sustentáveis (adesão às falsificações e endividamentos).

Desta forma, as preocupações ambientais surgem em segundo plano nas agendas de consumo destas mulheres. Os dados sinalizam que a sustentabilidade ambiental não é uma variável decisiva para as mulheres na ocasião das compras. Tecnologias de ponta, preço, estética, utilidade, facilidades de pagamento e sentimento de proporcionar conforto e felicidade (seja pessoal ou a outros) ainda são prioridade.

As problemáticas ambientais foram citadas por $11,86 \%$ das mulheres da amostra "B" (professoras e servidoras) e por 4,60\% das mulheres participantes do Programa Mulheres Mil (amostra "A"), no contexto destas mulheres existe a preocupação com recursos para alimentação e com abastecimento de água, considerando a repercussão da atual crise hídrica em Estados Brasileiros e as experiências ligadas à escassez na infância e juventude.

O olhar acerca destes percentuais deve considerar o acesso aos veículos de informação, as vivências cotidianas ligadas às limitações dos recursos e 
as atividades ligadas ao trabalho, considerando que as professoras e TAEs sentem a necessidade constante de atualização relacionada a estes e outros temas atuais, uma vez que trabalham em uma instituição de ensino, na qual projetos institucionais podem trazer à tona a emergência de repensar tais questões.

Foi observada pré-disposição para mudanças em relação às novas opções de produtos sustentáveis, na qual o desejo de mitigar os impactos ambientais exercita o desejo de mudanças não apenas na esfera individual e familiar, mas também coletiva. Significa dizer que as mulheres estão dispostas a ouvir, experimentar e mudar suas práticas de consumo, mesmo que de forma tímida inicialmente, embora o sentido de economia doméstica de recursos que repercute financeiramente, seja o viés que mais representa as duas amostras.

O mais difícil então, seria sensibilizar as mulheres em relação aos itens que gostam de comprar e que atribuem valor de merecimento. Estas comprinhas, geralmente cíclicas e permeadas por sentidos de complementaridade (Cf.: efeito Diderot, McCRACKEN, Grant; ROCHA, 2003), sensação de bem estar e vontade de agradar a si e aos outros, podem onerar o orçamento pessoal e domésticos com despesas advindas do impulso de comprar. Bolsas, sapatos, bijuterias, guloseimas, são vários os artigos que as mulheres compram por impulso e depois se arrependem ao observar a fatura do cartão de crédito.

Diante disto, nota-se a conexão com uma "ética razoável" que nos permita ter acesso aos produtos que apreciamos mesmos que estes não possuam atributos sustentáveis do ponto de vista socioambiental. Torna-se difícil conhecer aspectos relativos à origem, fabricação, logística e venda dos produtos em relação à sustentabilidade, visto que o sentimento de felicidade de aquisição de um bem ou serviço torna-se gratificante se considerados os esforços que proporcionaram a realização dos desejos e objetivos e podem deixar aspectos ambientais para segundo plano.

Em relação às professoras e TAEs observa-se maior mobilização pessoal e coletiva ligada ao enfoque da economia e da prática profissional. Deve- 
se lembrar que o IFS oferece incentivos por meio dos programas de pesquisa e extensão para o desenvolvimento de projetos com viés socioambientais, desta forma nos últimos anos pode-se notar a ampliação destes projetos. Já na amostra "A" (mulheres mil) algumas participantes citaram a preocupação em economizar água e energia elétrica.

Neste horizonte de transformações, nota-se pressões mercadológicas cada vez maiores no bojo da crescente responsabilização nas rotinas das mulheres. É presente também o estresse relacionado à gestão e passagem do tempo, aspectos estéticos e tecnológicos e valorização do processo de autonomia através do trabalho e do consumo como sinônimo de bem-estar. Ressalta-se ainda o destaque midiático a atributos femininos e poder de escolha (você pode, você merece) paralelo a imagens de papéis ligados ao biologismo e serviços domésticos.

No contexto de ampliação das responsabilidades, um dado importante refere-se à contribuição das mulheres na gestão das despesas do lar, indicando inclusive sua participação em gastos com pneus, combustíveis e outras despesas que diferem da frenquente indicação que as mulheres têm como prioridade a aparência e produtos de beleza.

É importante sinalizar a ampliação do diálogo com os entes do lar sobre a gestão da carreira, decisões de compras e demais assuntos, ressaltando a dificuldade de algumas mulheres da amostra "A" (Mulheres Mil) em negociar com seus cônjuges um possível retorno à escola e inserção no mercado de trabalho formal, por conta dos serviços domésticos e cuidado com os filhos.

Quanto a este aspecto, o acesso à escolaridade e ao trabalho formal repercute como o principal caminho para a geração de renda e autonomia, mas convive ainda com obstáculos como a falta de tempo, de rede de apoio como creches e escolas infantis de qualidade (e confiança). Por conseguinte, o consumo surge como forma de melhorar as condições de vida e "recompensar" os esforços empreendidos por meio do trabalho, seja este formal ou informal.

Confirma-se a hipótese de dissonâncias entre o percebido e o vivido em relação às práticas de consumo, considerando obstáculos internos (a exemplo da falta de motivação e informação, influência midiática e da moda 
ou compulsão em comprar) e externos (falta de coleta seletiva, saneamento básico, entre outros). Assim, o percebido ainda não se concretiza de forma plena no vivido destas mulheres, pois alguns obstáculos como à falta de informações sobre o consumo sustentável, falta de opções de coleta seletiva, de coleta de óleo de cozinha e outras ações ainda atrapalham participações efetivas e contínuas.

Quanto às mulheres investidas em cargos públicos (professoras e TAEs) o convite às práticas de consumo sustentável encontra-se na esfera da sensibilização individual do querer-dever (assim como indicado por Jonas 2006) que pode ou não estender-se a sua vida fora do lócus de trabalho.

É percebido que mulheres que partilham ideologicamente de pressupostos ligados à sustentabilidade ambiental procuram soluções para problemas cotidianos, buscando novos conhecimentos e sensibilizando mediante algumas ações ligadas a projetos de pesquisa e extensão, reuso do papel e redução do uso de copos descartáveis, ações estas que necessitam de um horizonte mais articulado em médio e longo prazo, com vistas a propiciar resultados duradouros.

Diante do exposto pode-se notar o estresse que emana hoje dos processos que relacionam o dia a dia e as práticas de consumo. Nos moldes de Bauman confirma-se que a rapidez, a descartabilidade, o sentimento de "desencaixe" são sintomas latentes da constante insatisfação em relação ao tempo e a sobrecarga de reponsabilidades, tantos das mulheres que estão fora do mercado de trabalho e não podem no momento aumentar seu acesso a bens e serviços quanto das mulheres que possuem agendas cheias de compromissos e que precisam dar conta dos diversos malabares que possuem nas mãos para equilibrar.

\section{REFERÊNCIAS BIBLIOGRÁFICAS}

1. BARBOSA, Lívia. Sociedade de consumo. 2.ed. Rio de Janeiro: Jorge Zahar, 2008. 67p. 

, Lívia; CAMPBELL, Colin. O estudo do consumo nas ciências sociais

3. contemporâneas. In.: BARBOSA, Lívia; CAMPBELL, Colin (Org.). Cultura, consumo e identidade. Rio de Janeiro: FGV, 2006.204p.

4. BARbOSA, Lívia; PORTILHO, Fátima.; VELOSO, Letícia. (Org.). et al. Consumo: cosmologias e sociabilidades. Rio de Janeiro: Muad X ; Seropédica, RJ; EDUR, 2009.156p.

5. BARDIN, Laurence. Análise de conteúdo. Tradutores L.A. Reto \& A. Pinheiro. Lisboa: Edições 70, 1977.

6. BAUMAN, Zygmunt. O mal-estar da pós-modernidade. Tradução Mauro Gama. 4.ed. Rio de Janeiro: Jorge Zahar Editora, 1998.

7. _. Modernidade Líquida. Tradução Plínio Dentzien. Rio de Janeiro: Jorge Zahar, 2001.

8. _ _ Vida Líquida. Tradução Carlos Alberto Medeiros. Rio de Janeiro: Jorge Zahar, 2007.

9. A sociedade individualizada:vidas contadas e histórias vividas. Tradução José Gradel. Rio de Janeiro: Jorge Zahar , 2008a.

10. _ Vida para o consumo: a transformação das pessoas em mercadorias. Tradução Carlos A. Medeiros. Rio de Janeiro: Jorge Zahar, 2008b.

11. BERGUE, Sandro Trescastro.Gestão de pessoas em organizações públicas: uma abordagem orientada para a administração Pública Municipal. Caxias do Sul, RS: EDUCS, 2005.599p.

12. BRASIL. Ministério da Educação. Consumo sustentável: manual de educação. Brasília: Consumers International/ MMA/MEC/IDEC, 2005. 160p.

13. BOTSMAN, Raquel; ROGERS, Roo. O que é meu é seu: como o consumo colaborativo vai mudar o nosso mundo. Tradução Rodrigo Sandernberg. Bookman: Porto Alegre, 2011, 09-25.

14. CANCLINI, Nestor. G. Consumidores e cidadãos: conflitos multiculturais da globalização.7.ed. Tradução Maurício S. Dias. Rio de Janeiro: UFRJ, 2008. 290p.

15. COOT, Nancy. F. A mulher moderna: o estilo americano dos anos vinte. In.: DUBY, Georges; PERROT, Michelle. História das mulheres: o século XIX. Portugal: Edições Afrontamento, 1991.

16. FONSÊCA, Flaviano Oliveira. O pensamento (Bio)Ético de Hans Jonas: filosofia e civilização tecnológica. 1.ed. Aracaju: IFS, 2014.

17. GIACOMINI FILHO, Gino. Meio ambiente \& consumismo. São Paulo:SENAC, 2008.

18. GREER, Germaine. A mulher inteira. Tradução Alda Porto. Rio de Janeiro: Record, 2001. 
19. GUERRA, Renata de Souza. Dimensões do consumo na vida social. 2011. $261 \mathrm{f}$. Tese de doutorado- Universidade Federal de Minas Gerais, Faculdade de Filosofia e Ciências Humanas, Belo Horizonte, 2011. Disponível em: <http://www. bibliotecadigital.ufmg.br/dspace/bitstream/handle/1843/BUOS-8G9NSW/dimensoes_do_consumo_na_vida_social.pdf?sequence=1>.Acesso em: 19 jan. 2014.

20. JONAS, Hans. O princípio responsabilidade: ensaio de uma ética para civilização tecnológica. Tradução Marijane Lisboa, Luiz Barros Montez. Rio de Janeiro: Contraponto, PUC Rio, 2006.

21. KUHN, Thomas S. A estrutura das Revoluções Científicas. São Paulo: Perspectiva, 1995. 262p.

22. LEFF, Enrique. Racionalidade ambiental: a reapropriação social da natureza. Rio de Janeiro: Civilização Brasileira, 2006. 513p.

23. Complexidade interdisciplinaridade e saber ambiental. In: PHILIPPI, Arlindo, et al. Interdisciplinaridade em ciências ambientais. São Paulo: Signus, 2000.317p.

24. S_ Saber ambiental: sustentabilidade, racionalidade, complexidade, poder. Tradução Lúcia M. E. Orth. 7. ed. Petrópolis, RJ: Vozes, 2009.494p.

25. LIPOVETSKY, Gilles. A terceira mulher: permanência e revolução do feminino. Tradução Maria João B. Reis. Lisboa: Instituto Piaget, Epistemologia e Sociedade, 1997.

26. __ A sociedade pós-moralista: o crepúsculo do dever e a ética indolor dos novos tempo democráticos. Tradução Armando Braio Ara. Barueri, SP: Manole, 2005.

27. McCRACKEN, Grant; ROCHA, Everardo (Org.). Cultura e consumo: novas abordagens ao caráter simbólico dos bens e das atividades de consumo. Tradução Fernanda Eugênio. Rio de janeiro: MAUAD, 2003

28. MILLER, Daniel. Teoria das compras: o que orienta as escolhas dos consumidores. São Paulo: Nobel, 2002. 191p.

29. MILLER, Geoffrey. Darwin vai às compras: sexo, evolução e consumo. Tradução Elena Gaidano. Rio de Janeiro: Bestseller, 2012. 513p.

30. SAMPIERI, R. Hernández.;COLLADO, Carlos F.; LÚCIO, Pila B. Metodologia de pesquisa. Tradução Fátima Conceição Murad et. al. 3.ed.São Paulo: McGraw-Hill, 2006.

31. SIQUEIRA, Rosana.R. Adolescentes e o consumo sustentável: percepções e estilos de vida. 2012. 225f. Dissertação de Mestrado - Universidade Federal de Sergipe, São Cristóvão, SE, 2012. 
32. SCHUDSON, M. Michael. Citizens, consumers and the good society. The Annals of the American Academy of Theory. Londres: Routledge, 2001.

33. SOLOMON, Michael R. O comportamento do consumidor: comprando, possuindo e sendo. Tradução Luiz Cláudio de Queiroz Faria. 9.ed. Porto Alegre: Bookman, 2011. 680p.

34. PORTILHO, Fátima. Sustentabilidade ambiental, consumo e cidadania. São Paulo: Cortez, 2005.

35. WAGNER, Helmurt. R.; (Org.). Fenomenologia e relaçôes sociais: textos escolhidos de Alfred Schütz. Rio de Janeiro: Zahar, 1979.

36. VASCONCELOS, Eduardo M. Complexidade e pesquisa interdisciplinar: epistemologia e metodologia operativa. 2.ed. Petrópolis, RJ:Vozes, 2002. 343p.

37. VEBLEN, Thorstein B. A teoria da classe ociosa: um estudo econômico das instituições. Tradução OLívia Krähenbühl. São Paulo: Pioneira, 1965.181p.

38. VERGARA, Sylvia C.; DAVEL, Eduardo (Org.) Gestão com pessoas e subjetividade. 3.ed. São Paulo: Atlas, 2009.

\section{Rosana Rosa Siqueira}

Doutora em Desenvolvimento e Meio Ambiente pela Universidade Federal de Sergipe. Mestrado em Desenvolvimento e Meio Ambiente pela Universidade Federal de Sergipe. Graduação em Administração pela Faculdade José Augusto Vieira. Graduação em Tecnologia em Saneamento ambiental pelo Instituto Federal de Sergipe.

\section{Maria José Nascimento Soares}

Doutora em Educação pela Universidade Federal do Rio Grande do Norte. Coordenadora do Programa de Pós-Graduação em Desenvolvimento e Meio Ambiente da Universidade Federal de Sergipe. 